\title{
THE OVERVIEW OF INVESTIGATION IN THE FIELD OF BANKNOTE DESIGN FOR VISUALLY IMPAIRED PEOPLE
}

\author{
Andrii Kyrychok \\ Department of publishing and editing \\ Institute of Publishing and Printing \\ National Technical University of Ukraine "Igor Sikorsky Kyiv Polytechnic Institute" \\ 37 Peremohy ave., Kyiv, Ukraine, 03056
}

\begin{abstract}
This essay aims to elaborate the technology when it comes to banknote making for visually impaired members of the society. The visually impaired are divided in three subgroups: color-blind, partially sighted and blind people. Their first needs are useful denomination features rather than security features, as they help them in determining a banknote's value. This study provides a historical overview of banknote design features for the visually impaired. Furthermore, it looks into the methodology of banknote tests for the color-blind, showing images of how the color-blind experience the euro banknotes. Two features are needed for every subgroup of the visually impaired to establish the banknote's value; one is not reliable. These two features are dedicated firstly to the relevant user group, but will also be used by others, including people with normal vision.
\end{abstract}

Keywords: visually impaired, banknote, design, technology, money making, currency, payment systems, cash money, color-blind, partially sighted.

\section{Introduction}

There is a tendency to forget that human beings who cannot lead a normal life, live among us. Those human beings have the difficulty to preform every day, seemingly simple tasks, among them recognizing banknotes. In this manner, it is a necessity that elements and features that can help visually impaired recognize and distinguish notes one from each other are included in the design and production of banknotes in all countries of the world.

The necessity to design and produce banknotes that are suitable for the visually impaired comes mainly from the fact that members of this particular group make a large percentage of worldwide population; that banknotes suitable for visually impaired are suitable for all members of the society; and that this is the right thing to do and their basic human right.

According to the figures managed by the World Health Organization, $5 \%$ of the world's population (253 million people) suffer from some type of visual disability, of which 36 million are totally blind, however, and as a result of different inclusion initiatives implemented in most countries of the world, have adapted environments, procedures and regulations to facilitate the lives of people suffering from disabilities of some kind and the visually impaired are among the beneficiaries of these legal, infrastructure adaptations and made conformation and in progress to provide a friendlier world within its limitations and to grant them the necessary protection for their disabilities [1].

The people blind of birth, have a greater capacity of tactile detection than the people with normal vision or partial visual disability, according to a study of the University McMaster in Washington (the United States) published in The Journal of Neuroscience. The brain records a vision, sound or touch in a split second, the research group, explored whether people with blindness would process the sense of touch more quickly. As scientists explain, "our findings reveal that one of the ways in which the brain adapts to the absence of vision is to accelerate the sense of touch." The ability to quickly process non-visual information probably increases the quality of life of the person. People with blindness who rely on an extraordinary degree of non-visual senses" [2].

Taking into account, through the empirical knowledge of the developed tactile capacity of the visual impaired from the 1825 Louis Braille, who was blind from the age of 13 as the result of an accident, perfected a system of 6 points in relief, based on another system of 8-point literacy, previously invented by a French soldier by the name of Charles Barbier de la Serre, to give orders without revealing the positions of the sentinels and taking advantage of the stimuli produced when 
palpating the reliefs of different types of products. They allowed the visually impaired, to know what product they were dealing with at any given moment, being these advances the first steps for the birth of today's Tiflotechnology [3].

In accordance with all the aspects related to the over-developed sense of touch of the vast majority of the visually impaired, including totally blind people, Bank initiated the development of favorable characteristics for the visually impaired through cleared numbers, and during 1971, they were the pioneers with the launching of the first notes with engraved marks for the recognition and differentiation, they varied their size in proportions of $6 \mathrm{~mm}$ by denomination for the visually impaired could easily recognize them, additionally they brought printed large numbers on a light background. The success of these initiatives originated mainly in the fact that they were the first in this successful act because the initiatives arose as a result of the research and work they carried out with a team of 40 blind people that they kept within their workforce [4].

It is also very important to point out that not all the advances made and implemented to facilitate the recognition of banknotes and their denominations, have been well received or accepted at all times by the totally blind people, complaining, in Austria, by the size of the money bill or demanding the non-placement of more dots on them, because these characteristics were assumed as effects of stigmatization towards them, thus they preferred a good general tactility instead, while contrary to their opinions, the National Organization for the visually impaired of Canada congratulated the Bank of Canada for the friendly designs of the banknotes.

The different initiatives studied and implemented with the active participation of groups of the blind and visually impaired in different degrees, by the central banks of each country and the institutions dedicated to the design and manufacture of banknotes of the world, have gone from designs with dots or raised-texture marks, emulating with the points the parameters established with the Braille system, due to the widespread use among the blind and the ease of use and recognition. The making of brands for the blind on bills establishes challenges of different types, such as brand type, manufacturing, quality, and durability [5].

Meanwhile, in other countries of the world, such as the United States, work groups were organized to obtain the best recommendations about the suitable marks for the visually impaired to include them in the new banknotes and to apply those changes to the new designs. Regarding the recommendations, related to the size of the money bills according to the denomination, enlarged numbers and with vivid colors. Some concerns emerged from those recommendations, such as the fact that only the difference in size would help the blind while the others features would only help the visually impaired. Additionally, the fact that US dollars banknotes are unchanged and that they are legal tenure and circulation since1929 until the time of its destruction [6].

The paper money of USA has no non-visual identification marks, so it is impossible for blind people to determine the value of banknotes without assistance, which results in problems to differentiate the banknotes denominations for a larger population of the visually impaired, including those who, due to aging, lose visual acuity. This detail is mentioned because currently, the authorities in charge of the design, development, and manufacture of the banknotes, are making the necessary efforts to make friendlier banknotes to the users to cover a broader range of citizens who will be facilitated for the recognition of the money bills and denominations.

In the world, there are currently 171 banknote issuers, and some of these entities have addressed the problem incorporating marks for recognition and differentiation, and there are also countries where blind people are provided with portable banknote readers with audio outputs that tell the denomination of the carried banknote [7].

The manufacture of a banknote is complex, due to the variety of processes that occur from the moment of its design, identifying a very important previous step at the time of the preparation of the base substrate on which the final design will be printed, and it is the impression of watermarks and placement of the security thread according to the corresponding denomination, at the moment of manufacturing the paper money rolls and is carried out by electrolysis processes kept in reserve by the banknote manufacturers. The paper money in most cases is a precise blend of cotton fibers that withstand wear and tear, giving it an approximate duration of 3 to 5 years under normal conditions of use. 
Three processes are identified in the manufacture of a banknote: offset printing process; screen printing process; calcography Process (Intaglio Printing).

During the Offset printing process, all background images of the banknote are printed, this printing is done using special permanent fast-drying inks that are very difficult to dilute once dry. Subsequently corresponds the time of screen printing, is made by printing complex images of different colors, which are printed one at a time to complete the final image, in this process the same inks used in the first process mentioned, corresponding, once the screen printing is completed, to the most complex process in the manufacture of banknotes as is the calcographic process. This is the most important of all the manufacturing processes of the banknotes and for its realization, engraved steel sheets are used with all the features that will highlight and give textures to the final banknotes [8].

The offset printing process is a smooth printing process, similar to the printing process of any magazine that contains a balanced combination of writing and images, which allows printing in different shades of color in a single pass, during the manufacture of banknotes. It is the first printing process because it is during this that all the images and details that will represent the bottom of the final image of the banknote are printed, it is done simultaneously on both sides of the sheet, and additional security elements are printed as They are: the look security features, hidden numbers, and anti-scan devices. Additionally, the design images are printed in fluorescent ink (invisible image), only observable with ultraviolet light [9].

The screen printing process is a printing technique used in the reproduction of documents and images on any material, and consists of transferring inks through a tensioned mesh, the passage of the ink is blocked in areas where there will be no image, leaving free the area where the ink will pass, it is a repetitive printing system, that once the first model has been achieved, the printing can be repeated hundreds and even thousands of times without losing definition, it is very suitable for printing large simultaneous batches of printed papers, such as series of banknotes.

The intaglio print is a printing technique dating from the fifteenth century used by goldsmiths and reproductions of works of art. from the last century it begins to be used in banknotes and today is one of the pillars in the security of these documents, it is the process used for the generation of a drawing or artistic composition in three dimensions on a plate of engraved metal, these engravings are filled with ink and then transferred to a paper by compressing the metal plate on the paper using a press that exerts a pressure of 20 tons to transfer the ink from the metal plate to the paper, leaving the pattern in high relief.

It is used for the generation of compositions in three dimensions to perform the dry stamping (without ink).

The engraving of the steel plates is done through one of two processes:

1. Hand engraving (engraver): using a cutting tool to remove material from a metal surface.

2. Etching: using acid to remove material from a metal surface.

The application of a great pressure causes a deformation in the surface of the engraved metal sheet, causing that the ink gets transferred to the paper in high relief, being possible to distinguish it to the touch easily, of this process the filaments or threads of ink are detached that in some Tickets are used as an additional security element and they are visible through the use of a magnifying glass. With this system, the main reasons, denomination are stamped and elements such as the latent image, micro prints and tactile marks for the visually and visually impaired are incorporated.

At this point we must mention the modern banknotes manufactured with polymers, which have been in circulation since 1988, the date on which the first units were issued by the Australian government as a safe option against counterfeiting, due to their particular characteristics, These bills are manufactured with a biaxially oriented polypropylene polymer (BOPP), which provides excellent qualities in terms of preservation and durability and resistance to weathering and use. The polymer banknotes also incorporate many security measures that are not available on traditional cotton paper tickets, making their counterfeiting much more complicated, likewise incorporating trademarks and bumps for recognition by the visually impaired and the blind [10]

The manufacture of the polymer banknotes is done in a similar way to that of the banknotes of cotton fiber in terms of offset, screen printing, and intaglio printing, however there are two spe- 
cific differentiated, the first is related to the preparation of the base substrate of polymers, which during the process of preparation in sheets, receives two layers of opaque white paint for each of the two surfaces except for this painting the windows that will be intentionally left transparent and a final protective varnishing process of the banknote once its printing process is ready. BOPP banknotes are resistant to folding, tearing, machine and dryer, difficult to burn and recyclable once they reach their useful life date [11].

The impression, placement or configuration of recognizable marks by the visually impaired or the blind ranges from the color of the banknote, individual geometric or series marks, groups of dots or individual, numbers enlarged in bright colors to the bumps of the Australian banknotes. This process of mark integration involves a physical or mechanical process that differs when it comes to cotton fiber or polymer banknotes whether it is applied during the printing process or subsequent to it, reminding that the processes vary according to the type of banknote that is being manufactured [12].

When analyzing the printing methodology of recognition marks that facilitate the identification and differentiation of the denominations of the banknotes by the visually impaired or the blind, must be recalled the printing processes to which the banknotes are subjected at the moment of fabrication, specifically to the process of intaglio printing to broaden the explanation of all the sub-processes actively involved in shaping and creating textured marks on the surface of banknotes in specific areas previously chosen through consultation work with visually impaired and blind people, being the best candidates and future users of these features.

Another relevant body of work was conducted by the Federal Reserve Bank of St. Louis, which highlighted the difficulties a banknote issuer faces when attempting to conduct a cost-benefit analysis of including accessible features on banknotes. In this study, it was noted that benefits accrue to a diverse group and at very different levels. For example, some low-cost features that assist the vision-impaired 9 Handheld electronic banknote readers are made available free of charge and distributed by a registered charity, CNIB, to blind individuals on behalf of the Bank of Canada. community (colors and numerals) also assist normal-sighted people to distinguish banknotes. On the other hand, the high-cost features (sizes and tactile features) that benefit the people with vision impairment may be extremely costly to implement for many other stakeholders.

\section{Methodology}

This essay will aim to discuss and elaborate the topic on "Banknote design for visually impaired people". This essay is divided into several main headings and subheadings. The main headings of this essay "Discussion" and "Results" are, in order to be better explained, broken down into certain subthemes which guide the topic in order to answer the main question of this essay: the technology when it comes to banknote making for visually impaired members of the society. In order to understand this essay some basic terms and the overview of this topic, done so far by nations and countries around the world and what is needed to be done, must be presented before the technology of banknote making for visually impaired people is discussed. In this manner, the importance of designing and producing banknotes for visually impaired people and an overview what have worldwide nations done so far in this area will be elaborated in the first place, while the technology of designing such banknotes will be presented in the final parts of this paper.

This essay was conducted by the use of the following methods: the historical method, the comparative method, the method of proof and omission and the method of classification.

This paper will aim to prove the following hypothesis:

"The design and production of banknotes must be suitable and user friendly to all members of the society, mainly those who are visibly impaired".

\section{Results}

Technology of banknote making for visually impaired people

In order to answer the main question of this essay and elaborate the technology when it comes to banknote making for visually impaired members of the society, the following question must be answered: How should a bank instruct the graphic designer to design banknotes that are 
suitable for the visually impaired? According to Hans de Heij and the study "banknote design for the visually impaired", "the answer to this question follows from the development phases of 'applied design': information, analysis, problem definition, planning and drafting” [13]. So, what are the needs of the visually impaired members of the society when it comes to designing and producing banknotes that are suitable for this group? According to Heij, their first needs are useful denomination features prior to security features, "as they help them in determining a banknote's value" [14]. In previous chapter, an overview of what has been done in some countries of the world has been given and some basic features of user friendly and easy to use banknotes when it comes to the visually impaired people can be distinguished. Features such as variable size banknotes, large numerals on banknotes, variable colors on banknotes, specially shaped patterns, specific engraved invisible markings, watermark features, machine identifiable features are some of the features designed so far in order to ease the use of banknotes for the visually impaired members of the community. Yet, due to tradition and issues of viability, there is no standard method that has been adopted as a worldwide standard [15]. The result is unanimity in approaching this problem and in technology of banknote making for visually impaired people.

The task of designing and producing money that is suitable for the visually impaired is easier today than it has ever been. Not only that, but in today's world virtual money is becoming more dominant than cash itself. Therefore, technology gave us more options. But still, it is very expensive and hard to find a unique solution and have a unique standard in all countries of the world. As it has been shown, every country has their own way how to include visually impaired persons into normal life and in this manner in the world today we can find various solutions. Among these official solutions made by the government, there are some "unofficial ones", developed by visually impaired community, due to the lack of an official design. The most common one can be found in the United States:

1) $\$ 1$ bill is left unfolded;

2) $\$ 5$ bill is folded end to end to make a square;

3) $\$ 10$ bill is folded in half lengthwise to make a long rectangle (and inserted in a wallet with the folded side up, so other bills are not inserted in the crease and lost when a $\$ 10$ is pulled out;

4) $\$ 20$ bill is folded into fourths (and may be placed in a separate compartment of the wallet);

5 ) when it comes to the USA it is very difficult to change banknote. Therefore technologies provide solutions. With the new technologies, it is possible to provide a new and better life for those who have visual difficulties".

When it comes to visually impaired members of the society, they are divided in three subgroups: color-blind, partially sighted and blind people. These different subgroups have different needs when it comes to design and the technology of banknote making. According to Heij, these needs, when it comes to design and the technology of banknote making for visually impaired people, can be expressed through the following:

1. Color-blind: When it comes to the color blind members of the community the need in the technology of banknote making is to "create a color scheme for all denominations suitable for both the color-blind and normal sighted people" also one should distinguish maximum color differences between successive denominations; one other aspect needed for this subgroup is that "the individual banknotes should be monochrome and vivid"; while "pastel tints (added white), avoid grey scale colors like olive green and brown (added black)" should be avoided.

2. Partially sighted: when it comes to the subgroup of the partially sighted members the denomination figure should be increased to a height of $22 \mathrm{~mm}$; the numerals should be used on the front and on the reverse as well and kept on the same location while a clear contrast between the numbers and the homogenous background should be established; also scientists suggests to "print one denomination figure as a dark number on a light background and the other vice versa: 'light on dark' [16]; clear silhouettes should be created on the front.

3. Blind: This subgroup "demands" the following features when it comes to the design and technology of banknote making: large and increasing length difference between the low denominations should be created while the high denominations do not need a length difference but it is preferred that it does have one; the height of all denominations can be the same and the preferable 
height is between $65-75 \mathrm{~mm}$ while an uniform height is the worldwide trend; all denominations should be provided with a coded tactile structure and the short and long edges of the notes should be used as well as well as the new digital engraving techniques with a higher relief and sharper slopes [17].

The world of technologies provides with various answer that can make our life easy. In that sense, those who are blind or visually impaired have more options today. But still, there are special problems when it comes to banknotes. Every solution that implemented is not still a permanent one. In this manner, when it comes to currency design for blind and visible impaired, it is possible to find various solutions.

Therefore, the design for currency depends on the awareness of the rest of the society that there are humans who have visual difficulties. Such awareness can, for example be found, in the premise of the European union: "Special attention to continue to be devoted to preparing certain categories of the population with particular difficulties of access to information such as elderly, blind people or people with impaired sight or hearing ... since these categories require a form of education rather than mere information; [the] stepping up of the training of trainers; and providing them ... from the last three months of 2001 with the appropriate sample sets of euro notes and coins, in accordance with the relevant security measures." [18].

Although the design can very, and is different from country to country, there are some criteria that must be included in this area; some of these elements and features were mentioned bellow.

The general impression of the banknote must be based on simplicity. This means that banknotes should identify very easily. Previously said will be explained in detail on the example of some of the worldwide currencies.

\section{Australian Dollar}

The Australian dollar has addressed the accessibility issue using a rather simple method: by making larger denominations as well as longer. Besides this, the Australian dollar has strong colors and contrasts suitable for the visually impaired.

\section{Euro}

As previously mentioned, the Euro banknotes were designed together with the help and input from Blind organizations. Euro banknotes have one rather simple distinguishing feature: big bills are big; little bills are little. Also, the notes have some intaglio printing, which provides relief marks that can be felt by touch.

\section{Canadian Dollar}

Besides the United States, Canada is the only other major currency that has banknotes that are all the same size. Yet, the Canadian dollar does have, contract to the US dollar, a distinguishing feature suitable for the visually impaired: tactile marks are built at the top right of bills. Also, different denominations are colored differently as well.

\section{Hong Kong Dollar}

Hong Kong has a very diverse palate when it comes to banknotes which include different features such as intaglio printing, different sizes, and different colors.

\section{Japanese Yen}

The Japanese Yen has special intaglio-printed tactile marks and uses different size for each bill. 6. Swedish Krona

Sweden has introduced different colors for the visually impaired and different sizes for the blind.

7. Swiss Franc

Switzerland uses different colors and sizes for its banknotes as well as intaglio marks and a perforated number that one can feel.

\section{British Pound}

British banknotes can be distinguished by size, and by color (to a certain level) [19].

Today it is possible to be aware that there are many solutions to this problem. In that sense, every problem, and this one in particular due to its sensitivity and importance, is, in fact, a global one. When it comes to aspect of technology and the design of banknotes, one must keep in mind that now we have different options available when it comes to the design of blind and color blind persons and this problem can be overcome very easily. Hence, the design of banknotes will be 
irrelevant for those with visual problems in the future. The new electronic devices are capable to replace color blindness and blindness. These kinds of devices are reliable and very useful. For now, their main defect is the price. This means that not everyone can use these kinds of devices and they must be adapted. In practice, this kind of devices is also adaptable to all of the new needed features, discussed previously in this paper.

One of those devices is MoneyTalker. "MoneyTalker's recognition technique is the transmission/reflection property of light. Colored lights are transmitted through the note and as each note is a different color, the amount of light that is transmitted through the note is different and dependent on the color of the note. Sensors positioned beneath the colored lights return values that are dependent on a note's coloring and light transmission characteristics.“ [20].

\section{Discussion}

The need for banknote design for visually impaired people

Every human being must be able to fully participate in everyday life and such full participation in today's society is, among other things, ,, being able to conveniently and confidentially exchange currency in everyday transactions, as when using public transportation or making purchases" [20]. "The ability to conduct financial transactions using bank notes is crucial to independent living; yet this can pose significant challenges for individuals who are blind or partially sighted." [21].

Banknotes that are not designed in a manner that „suite“ visually impaired people are in most cases uniform in size, color, and general design. In such cases visually impaired people can't distinguish banknotes from each another as such banknotes provide no basis for denominating by visually impaired members of the society. What is the result of this uniform in size, color and design? The result is that the "this sameness of size and color make it impossible for a blind person to locate the correct bills to make a purchase without some sort of assistance, or confirm that he or she has been given the correct change by the sales clerk." [20]

"Visual identification of denomination by people with low vision is generally so challenging that many revert to techniques used by people who are blind." [20]

A large number of the population is in fact visually impaired; according to the data that the World Health Organization (WHO) has (from the 2002), "there are worldwide more than 161 million people visually impaired; among them 124 million have low vision and 37 million are blind" [22].

In this manner, banknotes, as well as coins, should be designed in a manner that suites the visually impaired community, with such features that visually impaired people can handle with confidence. Such banknotes should be easy to use and user friendly when it comes to the visually impaired members of the community. Only if all members of the society, including those who are blind or partially sighted, have a barrier-free access when it comes to banknotes, a currency can be the most effective as a means of payment.

Work done so far in this area by countries and central banks

Guided by the principle of co-operation between the European Central Bank and the European Blind Union (EBU) during the currency design phase of the 1990s, which is still applicable to all countries and currencies of the world, that a ,good design for the blind and partially sighted is a good design for everyone ", the interest of all world governments when it comes to designing banknotes for visually impaired should be based on this principle. This task is in the hands of each and every country in the world and their national banks. This has, in fact, been recognized as a problem and an area of focus and increasing concern for bank note issuers around the globe, which recognize the special needs of this particular group and the importance of designing and producing banknotes in a manner to be suitable for this growing subset of the population, as The Bank of Canada correctly noted [23], meeting the meet the needs of all sections of the community, as the Reserve bank of Australia correctly noted as well [24]. In this manner, a large number of countries have already designed banknotes so they suit the needs of the visually impaired members of the society. Scientists list some of the ways in which certain countries of the world have come to this problem and designing the banknotes so that they can also benefit the visually impaired: 
"Canadian banknotes are printed with a tactile feature in the corner so the visually impaired can easily tell what denomination they're holding Brazil, Thailand, Malawi, and Bahrain use embossing. China's banknotes are said to include Chinese Braille. Hong Kong followed China's lead. And all Chilean banknotes have tactile features in one corner England uses different-sized notes, with each using different colored shapes - similar in many ways to the design of euro banknotes.", nothing further on that "Only the United States prints banknotes are identical in size and color in all their denominations." [25] Beside the named countries, it is important to note that De Nederlandsche Bank has done a large amount of research in order to address the needs of the visually impaired and was the first one to introduce clear number and marks for the blind (doing so in 1971) [26].

When it comes to the United States, a lawsuit has been brought by the American Council of the Blind (ACB), and the result is that the Treasury Department must make, under the Rehabilitation Act of 1973, the US currency accessible and suitable to the blind and visually impaired members of American society. Yet, the reaction of the government is slow, and it is estimated that this will not be done until the 2020:

"The U.S. government will continue to research a raised tactile feature for use on the next redesigned Federal Reserve note and will continue to add large, high-contrast numerals and different colors to each redesigned note denomination that it is permitted by law to alter. The process for redesigning Federal Reserve notes is complex and time intensive. Notes with any new features are not expected to be in circulation before 2020." [27].

Nevertheless, it is a great advantage that this aspect has been in fact recognized as a problem in other countries of the world and that they have adapted the design and printing of their banknotes to adapt them to the blind and short-sighted members of the community and most of the "central banks feel the need to do something for the visually impaired" while "the national organizations promoting the interests of the visually impaired are consulted when new banknote series are to be designed" [27].

\section{Conclusion}

The world of visually impaired people is difficult enough. In the today's social framework we are capable to overcome those difficulties in many ways. New technologies provide us with new opportunities.

In the case of banknotes for visually impaired people it is evident that there is no unique solution. Every country has its own way to deal with this problem. In practice it is evident that every day one can find one new solution that gives more opportunity for the those who don't have normal conditions for consuming life.

Today most of the banknotes incorporate microchips and various other marks. This means that a visually impaired person can, with the help of new technological gadgets, overcome the problem of currency identification.

Nevertheless, it is not limited when it comes to options. Some ideas are expensive some are not. In that sense the design of banknotes must be in accordance with every citizen. We are all equal. In that sense, it is necessary to create better conditions for every member of the society.

\section{References}

[1] Heij, H. de. (2009). Banknote design for the visually impaired Vol. 7. Occasional Studies, 168.

[2] Laming, D. R. J. (1986). Sensory Analysis. San Diego: Academic Press.

[3] Currency Features for Visually Impaired People (1995). doi: 10.17226/4828

[4] Butterly, A. (2016, August 31). How new bank notes will help the visually-impaired community. BBC Newsbeat. Available at: http://www.bbc.co.uk/newsbeat/article/37231241/how-new-bank-notes-willhelp-the-visually-impaired-community Last accessed: 12.03.2018

[5] Samuel, C. (2010). Making Bank Notes Accessible for Canadians Living with Blindness or Low Vision. Bank of Canada Review, 29-36. Available at: https://www.bankofcanada.ca/wp-content/uploads/2011/08/samuel.pdf Last accessed: 04.03.2018 
[6] Identifying US Currency. Available at: http://www.afb.org/info/living-with-vision-loss/using-technology/accessible-identification-systems-for-people-who-are-blind-or-visually-impaired/-identifying-us-currency-/1235 Last accessed: 09.03.2018

[7] Wolff-Mann, E. (2015, October 15). How Blind People Tell Money Denominations Apart. Money. Available at: http:/time.com/money/4073753/blind-people-tell-money-bills-apart/ Last accessed: 15.03.2018

[8] Lederman, S. J., Hamilton, C. (2002). Using Tactile Features to Help Functionally Blind Individuals Denominate Banknotes. Human Factors: The Journal of the Human Factors and Ergonomics Society, 44 (3), 413-428. doi: 10.1518/0018720024497646

[9] Springer, K., Subramanian, P., Turton, T. (2015). Australian Banknotes: Assisting People with Vision Impairment. Available at: https://www.rba.gov.au/publications/bulletin/2015/mar/pdf/bu-0315-1.pdf

[10] Airey, D. (2013, July 15). Banknotes for the visually impaired. Graphic designer. Available at: https://www.davidairey.com/banknotes-for-the-visually-impaired/ Last accessed: 08.03.2018

[11] Abbott, G. (1994, March 30). Presentation to the Committee on Currency Features Usable by the Visually Impaired.

[12] Benson, V., Marano, M. A. (1994). Current estimates from the National Health Interview Survey. Vital and Health Statistics, 10 (189), 94-1517.

[13] Cholewiak, R. (1994, March 30). Presentation to the Committee on Currency Features Usable by the Visually Impaired.

[14] Genensky, S. (1978). Data concerning the partially sighted and functionally blind. Journal of Visual Impairment and Blindness, 72 (5), 177-180.

[15] Legge, G. E.; Shipley, R. M., Lam, D. M.-K. (Eds.) (1993). The role of contrast in reading: Normal and low vision. Contrast Sensitivity. Cambridge: Massachusetts Institute of Technology Press, 269-287.

[16] Genensky, S. (1994, March 30). Personal communication to the Committee on Currency Features Usable by the Visually Impaired.

[17] Jewish Guild for the Blind (1992). Photos taken from visual impairment poster. New York: The Jewish Guild for the Blind.

[18] Legge, G. E. (1994, February 23). Presentation to the Committee on Currency Features Usable by the Visually Impaired.

[19] Maurer, M. (1994, March 29). Presentation to the Committee on Currency Features Usable by the Visually Impaired.

[20] Legge, G. E., Rubin, G. S., Luebker, A. (1987). Psychophysics of reading-V. The role of contrast in normal vision. Vision Research, 27 (7), 1165-1177. doi: 10.1016/0042-6989(87)90028-9

[21] Pitts, D. G.; Sekuler, R., Kline, D., Dismukes, K. (Eds.) (1982). The effects of aging on selected visual functions: Dark adaptation, visual acuity, stereopsis, and brightness contrast. Aging and Human Visual Function. New York: Alan R. Liss, Inc., 131-159.

[22] Miller, G. A. (1956). The magical number seven, plus or minus two: some limits on our capacity for processing information. Psychological Review, 63 (2), 81-97. doi: 10.1037/h0043158

[23] National Advisory Eye Council (1993). Vision Research-A National Plan: 1994-1998. National Institutes of Health Publication, 93-3186.

[24] Council Committee on Vision, NRC. Washington: National Academy Press.

[25] NRC (National Research Council) (1994). Measurement of Visual Field and Visual Acuity for Disability Determination. National Research

[26] Nelson, K. A., Dimitrova, E. (1993). Severe visual impairment in the United States and in each state, 1990. Journal Visual Impairment and Blindness, 87 (3), 80-85. 